\title{
Comparison of Cardiorespiratory Responses during Body Weight- Supported Treadmill and Standard Treadmill Exercise
}

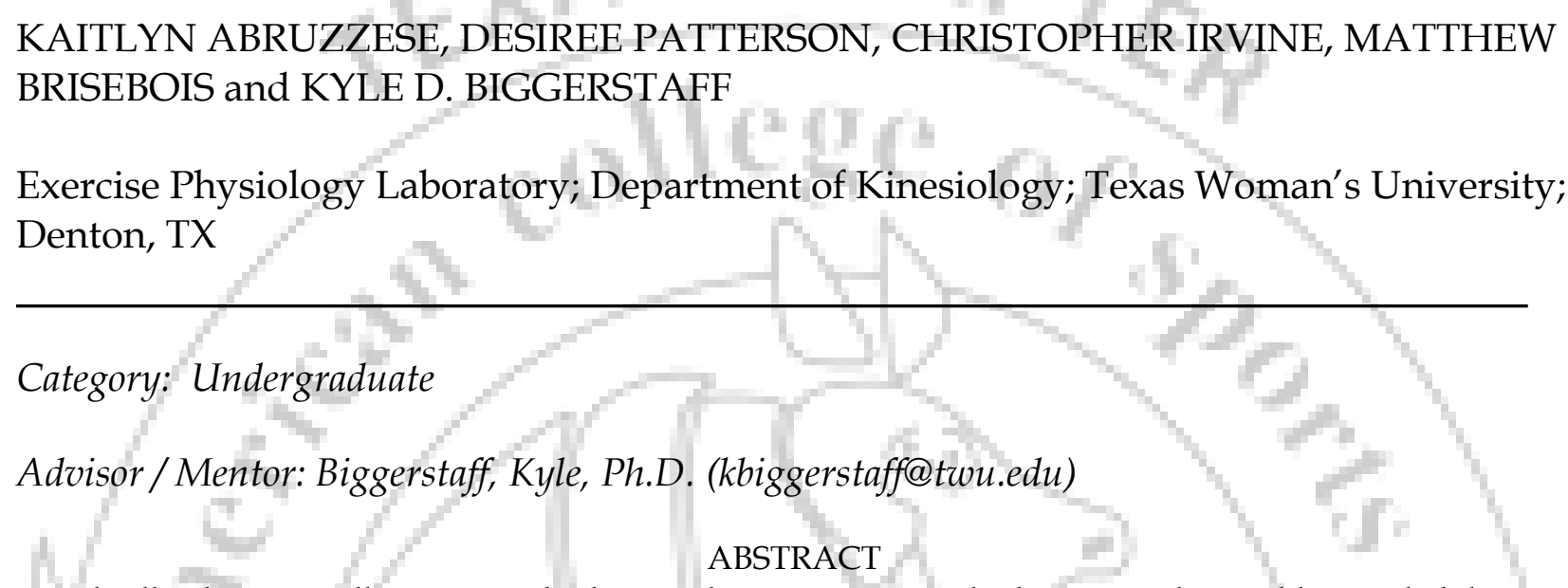

Treadmills that partially support body weight are increasingly being used in athletic rehabilitation settings. The cardiorespiratory response during this type of exercise has been reported in very few published studies. This study was designed to determine the cardiorespiratory response during three exercise intensities during standard treadmill exercise (ST) and body weight-supported treadmill exercise (BWST). In random order, a total of 10 healthy, 18-44 yr old adults (6 males, 4 females) performed BWST and ST trials. Identical exercise sessions were performed on each treadmill except $25 \%$ of body weight was supported during BWST exercise such that each participant carried $75 \%$ of true body weight. On each treadmill a two-minute warm up was performed at $2 \mathrm{mph}$ and $0 \%$ grade, followed by 6 minutes of exercise at 3\% grade at each of the following treadmill velocities: $3 \mathrm{mph}, 4.5 \mathrm{mph}$, and $6 \mathrm{mph}$. Expired respiratory gases were analyzed each minute. Steady state heart rate, $\mathrm{VO}_{2}, \mathrm{VCO}_{2}$ and RER were calculated as the average value during the final three minutes of each 6 min exercise stage. Blood pressure and RPE were recorded during the final minute of each stage. A $2 \times 3$ repeated measures ANOVA was used to determine significant differences at the $p<.05$ level. Post hoc analyses were determined using a LSD method. There was a significant difference in absolute $\mathrm{VO}_{2}$ between ST and BWST at $4.5 \mathrm{mph}(2.14 \pm .39 \mathrm{v}$ $1.42 \pm .27, \mathrm{p}<.05)$ and $6 \mathrm{mph}(2.75 \pm .58 \mathrm{v} 1.79 \pm .40 \mathrm{~L} / \mathrm{min}, \mathrm{p}<.05)$. Relative $\mathrm{VO}_{2}$ was significantly different at each exercise intensity and treadmill (ST v BWST: $16.0 \pm 1.1 \mathrm{v} 13.6 \pm 1.2 ; 31.2 \pm 2.0 \mathrm{v} 20.6 \pm 2.4 ; 39.8 \pm 1.9 \mathrm{v}$ $\left.25.8 \pm 2.9 \mathrm{ml} \cdot \mathrm{kg}^{-1} \cdot \mathrm{min}^{-1}, \mathrm{p}<.05\right)$. There was a significant difference in $\mathrm{VCO}_{2}$ between the ST and BWST at 4.5 $\mathrm{mph}(2.10 \pm .43 \mathrm{v} 1.32 \pm .26 \mathrm{~L} / \mathrm{min}, \mathrm{p}<.05)$ and $6 \mathrm{mph}(2.88 \pm .63 \mathrm{v} 1.68 \pm .39 \mathrm{~L} / \mathrm{min}, \mathrm{p}<.05)$. There was a significant difference $(\mathrm{p}<.05)$ in RER between the ST $(1.05 \pm .08)$ and BWST $(.94 \pm .06)$ at $6 \mathrm{mph}$. The HR was significantly different $(\mathrm{p}<.05)$ between ST and BWST at $4.5 \mathrm{mph}(162 \pm 17 \mathrm{v} 128 \pm 17 \mathrm{bpm})$ and $6 \mathrm{mph}(182 \pm 13$ $\mathrm{v} 146 \pm 17 \mathrm{bpm})$. There was no interaction effect for SBP, but SBP increased significantly on the ST (144 \pm 20 v $163 \pm 25$ v $175 \pm 22 \mathrm{mmHg}, \mathrm{p}<.05)$ and BWST $(128 \pm 11$ v $143 \pm 13$ v $155 \pm 16 \mathrm{mmHg}, \mathrm{p}<.05)$ at each exercise intensity. There were no significant differences in DBP at any exercise intensity on either ST or BWST. There was a significant difference $(\mathrm{p}<.05)$ in RPE on the ST at $6 \mathrm{mph}(15 \pm 1), 4.5 \mathrm{mph}(12 \pm 1)$, and $3 \mathrm{mph}$ $(9 \pm 1)$. There appears to be a lower cardiorespiratory response to graded exercise between body weight supported and traditional treadmills. 


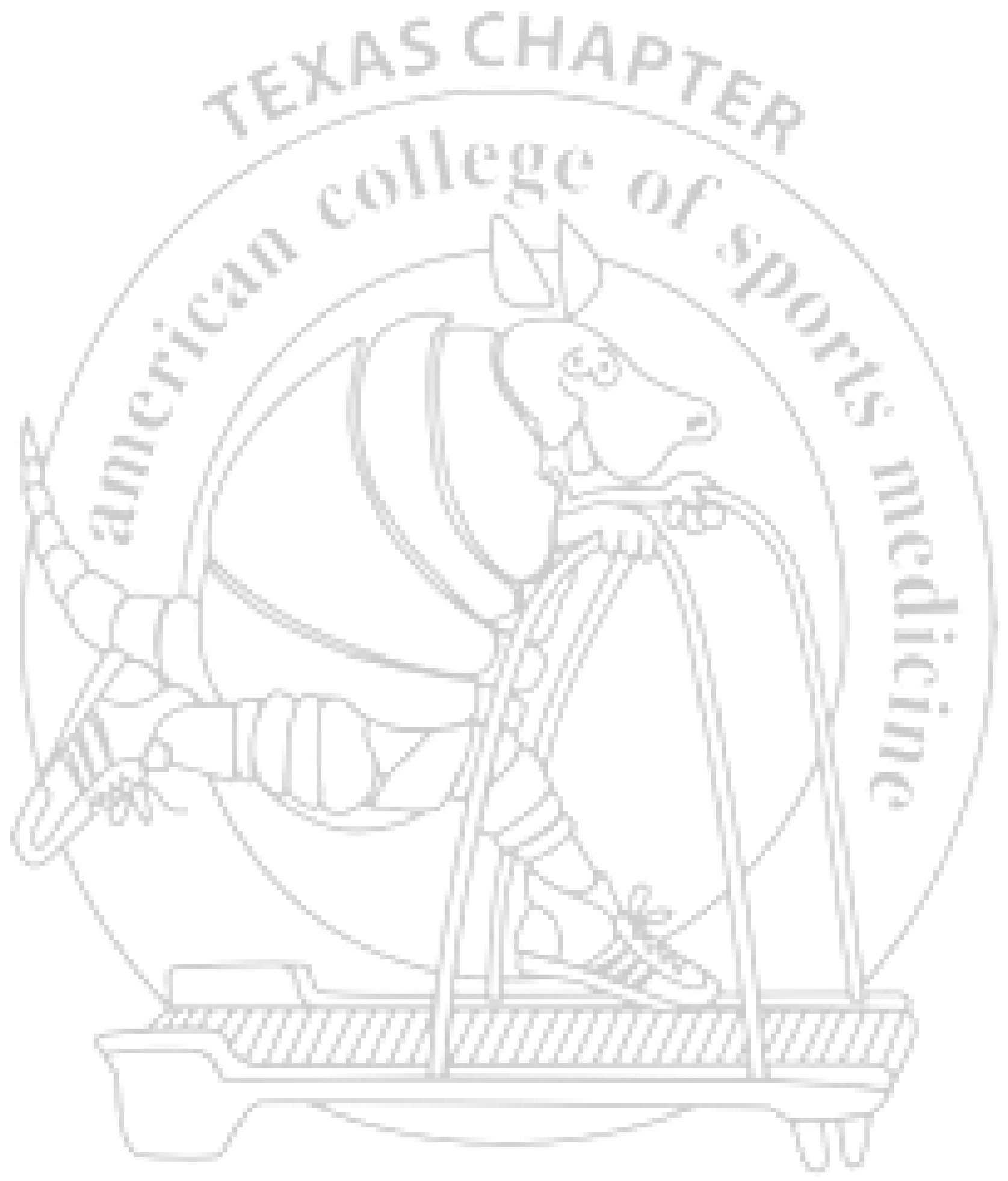

International Journal of Exercise Science

wWw.tacsm.org 